University of Nebraska - Lincoln

DigitalCommons@University of Nebraska - Lincoln

Faculty Publications from the Department of Electrical \& Computer Engineering, Department Electrical and Computer Engineering

$1-25-2006$

\title{
Catalytical growth of carbon nanotubes/fibers from nanocatalysts prepared by laser pulverization of nickel sulfate
}

\author{
J. Shi \\ University of Nebraska-Lincoln \\ Yongfeng Lu \\ University of Nebraska-Lincoln, ylu2@unl.edu \\ K. F. Tan \\ University of Nebraska-Lincoln \\ Xinwei Wang \\ University of Nebraska-Lincoln, xwang3@unl.edu
}

Follow this and additional works at: https://digitalcommons.unl.edu/electricalengineeringfacpub

Part of the Electrical and Computer Engineering Commons

Shi, J.; Lu, Yongfeng; Tan, K. F.; and Wang, Xinwei, "Catalytical growth of carbon nanotubes/fibers from nanocatalysts prepared by laser pulverization of nickel sulfate" (2006). Faculty Publications from the Department of Electrical and Computer Engineering. 91.

https://digitalcommons.unl.edu/electricalengineeringfacpub/91

This Article is brought to you for free and open access by the Electrical \& Computer Engineering, Department of at DigitalCommons@University of Nebraska - Lincoln. It has been accepted for inclusion in Faculty Publications from the Department of Electrical and Computer Engineering by an authorized administrator of DigitalCommons@University of Nebraska - Lincoln. 


\title{
Catalytical growth of carbon nanotubes/fibers from nanocatalysts prepared by laser pulverization of nickel sulfate
}

\author{
J. Shi and Y. F. Lu ${ }^{\text {a) }}$ \\ Department of Electrical Engineering, University of Nebraska-Lincoln, Lincoln, Nebraska 68588-0511 \\ K. F. Tan and X. W. Wang \\ Department of Mechanical Engineering, University of Nebraska-Lincoln, Lincoln, Nebraska 68588-0656
}

(Received 20 July 2005; accepted 13 December 2005; published online 27 January 2006)

\begin{abstract}
Dispersed nickel sulfate $\left(\mathrm{NiSO}_{4}\right)$ microclusters on $\mathrm{Si}$ substrates were fragmented by pulsed excimer laser irradiation to serve as catalysts for carbon nanotube/nanofiber (CNT/CNF) growth. At proper fluences, $\mathrm{NiSO}_{4}$ clusters were pulverized into nanoparticles. The sizes of clusters/nanoparticles were found to be dependent on laser fluence and laser pulse number. By increasing the laser fluence from 100 to $300 \mathrm{~mJ} / \mathrm{cm}^{2}$, the size of disintegrated particles decreased drastically from several micrometers to several nanometers. It was found that laser-induced disintegration of as-dispersed $\mathrm{NiSO}_{4}$ clusters was mainly due to physical fragmentation by transient thermal expansion/ contraction. Thermal melting of nanoparticles in a multipulse regime was also suggested. Hot-filament chemical vapor deposition (HFCVD) was used for growth of CNTs from the pulsed-laser treated catalysts. For samples irradiated at 100 and $200 \mathrm{~mJ} / \mathrm{cm}^{2}, \mathrm{CNFs}$ were dominant products. These $\mathrm{CNFs}$ grew radially out of big $\mathrm{NiSO}_{4}$ clusters, forming dendritic $\mathrm{CNF}$ bunches. For samples irradiated at $300 \mathrm{~mJ} / \mathrm{cm}^{2}$, dense multiwalled carbon nanotubes (MWCNFs) with uniform diameters were obtained. It is suggested that elemental $\mathrm{Ni}$ was formed through thermal decomposition of $\mathrm{NiSO}_{4}$ clusters/nanoparticles during HFCVD. The size and the shape of the Ni aggregation, which were determined by the initial size of $\mathrm{NiSO}_{4}$ clusters/nanoparticles, might affect the preference in the synthesis of CNTs or CNFs. (C) 2006 American Institute of Physics.
\end{abstract}

[DOI: 10.1063/1.2165403]

\section{INTRODUCTION}

In the past decade, carbon nanotubes (CNTs) have been widely studied due to their remarkable physical properties. ${ }^{1}$ A large variety of applications, such as field emission displays, ${ }^{2,3}$ nanoelectronic transistors ${ }^{4,5}$ and sensors, ${ }^{6}$ require well-controlled fabrication of high-quality CNTs. Current CNT synthesis methods include laser ablation, ${ }^{7}$ arc discharge, ${ }^{8}$ thermal chemical vapor deposition (CVD), ${ }^{9}$ plasma-enhanced CVD (PECVD), ${ }^{10}$ hot-filament CVD (HFCVD) ${ }^{11}$ and laser-assisted CVD. ${ }^{12}$ In most processes, optimization of catalyst preparation is one of the key steps to grow CNTs with desired diameters and size distributions. ${ }^{13,14}$ Conventional catalyst preparation methods include thermal annealing of $\mathrm{Ni}, \mathrm{Co}, \mathrm{Fe}$ thin films prepared by sputtering ${ }^{15}$ and electron beam evaporation. ${ }^{16}$ Solution-based catalysts ${ }^{9,17}$ were also successfully developed to obtain single-walled CNTs. Plasma ion bombardment of metallic thin films for nanometallic catalysts was also developed, ${ }^{18,19}$ especially for PECVD synthesis of CNTs. Generally, monodispersed and uniformly distributed nanocatalysts are desirable for catalytic growth of CNTs.

Recently, there is an increasing interest in pulsed-laser processing of nanoparticles. ${ }^{20-23}$ Nanocatalysts were fabricated by excimer laser ablation of thin transitional metal films for CNT growth. ${ }^{20,21}$ Due to the surface plasmon reso-

\footnotetext{
a) Author to whom correspondence should be addressed; electronic mail: ylu2@unl.edu
}

nance of metallic nanoparticles under laser irradiation, monodispersed metallic particles with tunable particle sizes can be generated by laser irradiation at different wavelengths. $^{22,23}$ One of the advantages of pulsed-laser processing over conventional thermal annealing is that it only induces transient temperature increase at the sample surface. Therefore, universal heating of samples can be avoided. In addition, pulsed-laser processing is an ultrafast process and can be performed in ambient atmosphere..$^{20,22,23}$

In this study, we demonstrated a method using pulsed excimer laser to generate $\mathrm{NiSO}_{4}$ nanoparticles as catalysts for $\mathrm{CNF} / \mathrm{CNT}$ growth. CNTs grown from nanocatalysts, which were generated under optimized laser parameters, were highly uniform in diameters. In the investigation of mechanisms in laser pulverization of $\mathrm{NiSO}_{4}$ clusters, we found that the process was mainly a physical process of laser fragmentation. Effects of initial $\mathrm{NiSO}_{4}$ cluster/nanoparticles size on catalytic CNT/CNF growth were also investigated.

\section{EXPERIMENT}

A $0.1 \mathrm{~N} \mathrm{NiSO}_{4}$ solution was prepared by dissolving $1.3 \mathrm{~g}$ of $\mathrm{NiSO}_{4} \cdot 6 \mathrm{H}_{2} \mathrm{O}$ in $50 \mathrm{ml}$ deionized (DI) water by sonication. Silicon substrates were ultrasonically cleaned in acetone and methanol sequentially to remove organic contaminations. A thin native oxide was kept on the Si substrates to ensure that the substrates were hydrophilic ${ }^{24}$ so that the $\mathrm{NiSO}_{4}$ solution could be uniformly adsorbed on the substrate surfaces. Cleaned silicon substrates were dipped into the 


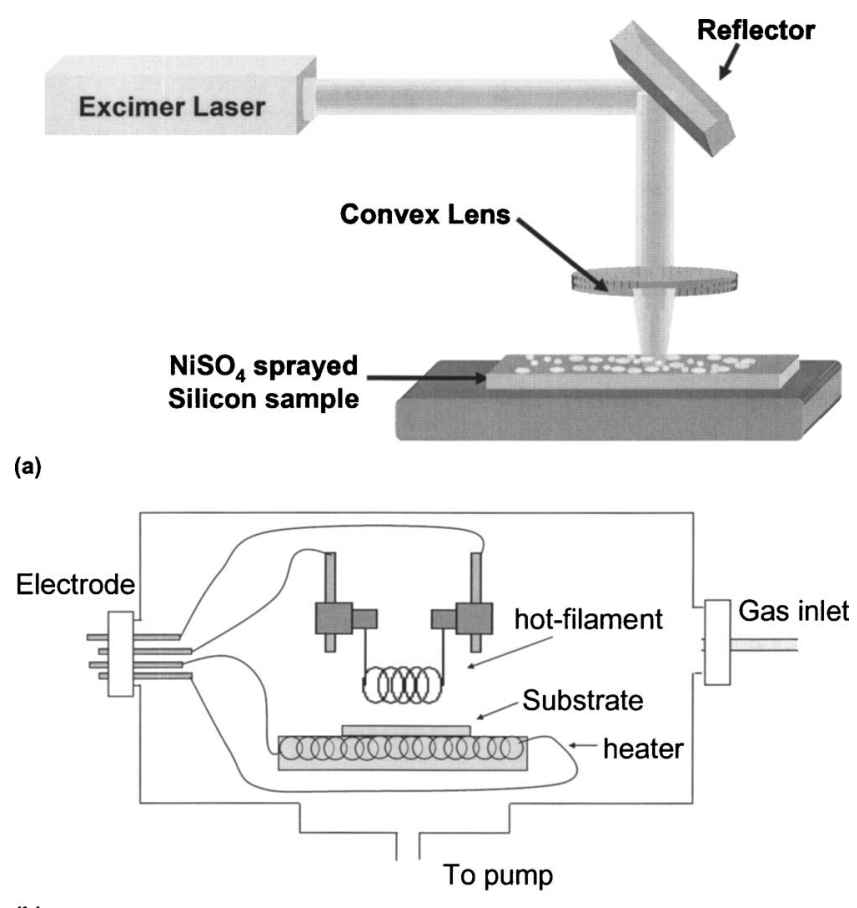

(b)

FIG. 1. Experimental setup of (a) laser pulverization of $\mathrm{NiSO}_{4}$ clusters by focused excimer laser and (b) hot-filament CVD system for CNT/CNF growth

$\mathrm{NiSO}_{4}$ solution and blown dry using compressed air. A monolayer of $\mathrm{NiSO}_{4}$ microclusters were then formed on the Si substrates. A KrF excimer laser (Lambda Physik Compex 205 , wavelength $=248 \mathrm{~nm}$, pulse duration $=23 \mathrm{~ns}$ ) was used to break the $\mathrm{NiSO}_{4}$ clusters into smaller clusters and nanoparticles, as illustrated in Fig. 1(a). In this study, the laser energy ranged from 128 to $380 \mathrm{~mJ} /$ pulse, with beam sizes from 0.3 to $3.8 \mathrm{~cm}^{2}$. The laser fluences and pulse numbers were in ranges of $100-300 \mathrm{~mJ} / \mathrm{cm}^{2}$ and $5-30$ pulses, respectively, with the repetition rate kept at $5 \mathrm{~Hz}$. The samples after laser treatment were placed in a hot-filament vacuum chamber, as shown in Fig. 1(b). The chamber was first pumped to a base pressure of $1 \times 10^{-4}$ Torr. The samples were then back heated to $480{ }^{\circ} \mathrm{C}$ before carbon-feedstock gases were introduced into the chamber. Ammonia and acetylene $\left(\mathrm{NH}_{3} / \mathrm{C}_{2} \mathrm{H}_{2}\right)$ gas mixture, with a volume ratio of 3 , was introduced into the chamber. During the process, reaction pressure was kept at $10 \pm 1$ Torr. A tungsten filament was kept about $4 \mathrm{~mm}$ above the substrate surface. During the process, the filament temperature was kept at around $1400{ }^{\circ} \mathrm{C}$. An atomic force microscope (Digital Instruments Nanoscope IIIa Dimension 3100 SPM) was used for characterization of the laser-pulverized $\mathrm{NiSO}_{4}$ nanoparticles. Statistical size distributions of clusters and nanoparticles were analyzed by a computer software "Image J."25 A Hitachi S-4700 field-emission scanning electron microscope was used to investigate the morphologies of $\mathrm{NiSO}_{4}$ clusters/particles and CNTs/CNFs. Energy dispersive x-ray (EDX) analysis was carried out in a Hitachi S3000N VP-SEM for qualitative elemental analysis. During the EDX measurements, the acceleration voltage and scanning window were fixed to $20 \mathrm{kV}$ and $200 \times 400 \mathrm{~nm}$, respectively. A FEI Tecnai G2 F30 Su-
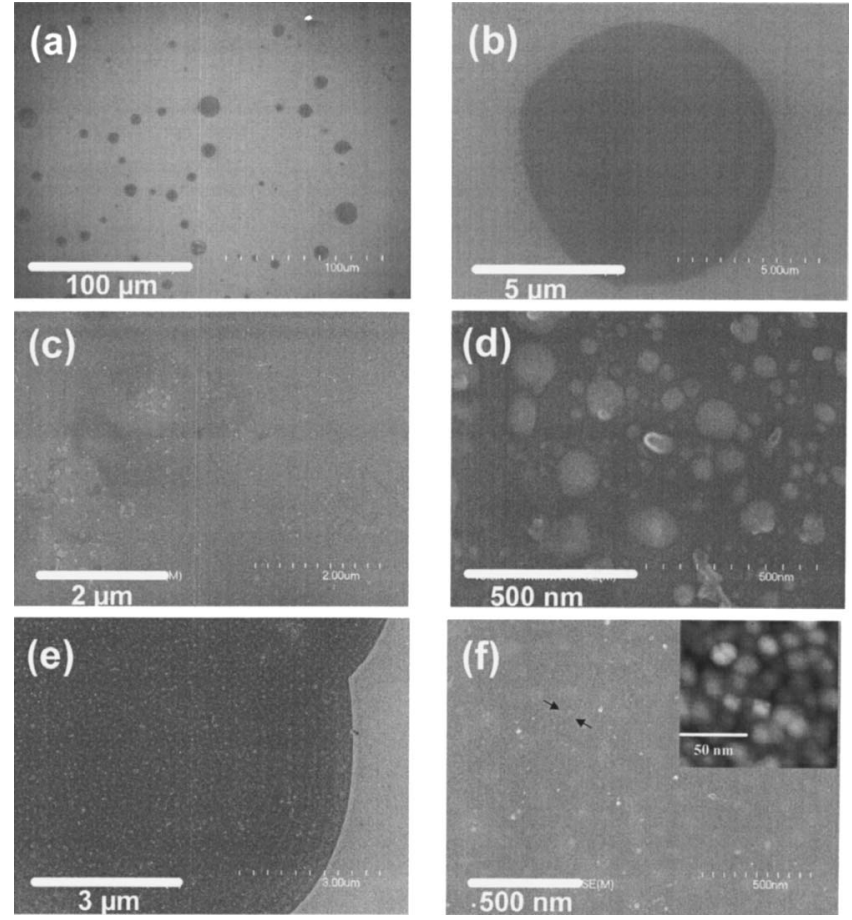

FIG. 2. SEM micrographs of laser-irradiated samples at different fluences. (a) and (b) $100 \mathrm{~mJ} / \mathrm{cm}^{2}$, (c) and (d) $200 \mathrm{~mJ} / \mathrm{cm}^{2}$, and (e) and (f) $300 \mathrm{~mJ} / \mathrm{cm}^{2}$. Pulse numbers were fixed at 30 pulses. The inset of (f) is an AFM image of a typical grey island, indicated by an arrow shown in (f).

pertwin field-emission gun scanning transmission electron microscope (FEG STEM) operating at $300 \mathrm{kV}$ was used for high-resolution TEM (HRTEM) characterization.

\section{RESULTS AND DISCUSSION}

\section{A. Laser pulverization of $\mathrm{NiSO}_{4}$ microclusters}

Figure 2 shows the SEM micrographs of silicon substrates dispersed with $\mathrm{NiSO}_{4}$ clusters after laser irradiation at 100,200 , and $300 \mathrm{~mJ} / \mathrm{cm}^{2}$ for 30 pulses. Figures 2(a) and 2(b) show samples irradiated at a fluence of $100 \mathrm{~mJ} / \mathrm{cm}^{2}$ for 30 pulses. As shown in Fig. 2(a), $\mathrm{NiSO}_{4}$ clusters with sizes ranging from $100 \mathrm{~nm}$ to $10 \mu \mathrm{m}$ were sporadically dispersed on the silicon surface. A close-up view of a cluster in Fig. 2(a) is shown in Fig. 2(b). The shape of the $\mathrm{NiSO}_{4}$ cluster after laser irradiation was cabochon-like bead, with a convex top and a flat back. atomic force microscopy (AFM) characterization indicates that the diameters and thicknesses were in the order of a few micrometers and hundreds of nanometers, respectively. Notice that the size distribution of clusters were similar to that of the as-dispersed samples, which indicates that $\mathrm{NiSO}_{4}$ clusters remained almost intact under laser irradiation at $100 \mathrm{~mJ} / \mathrm{cm}^{2}$ for 30 pulses. Figures 2(c) and 2(d) show the SEM micrographs of samples irradiated at $200 \mathrm{~mJ} / \mathrm{cm}^{2}$ for 30 pulses. The Si surface was covered with disintegrated particles. The particle sizes varied in a wide range and the shapes were irregular. As shown in Fig. 2(e), the dark region corresponds to a big cluster of $\mathrm{NiSO}_{4}$ asdeposited from the solution. With a fluence of $300 \mathrm{~mJ} / \mathrm{cm}^{2}$ and a pulse number of 30 , the surface of the $\mathrm{NiSO}_{4}$ cluster was roughened, showing densely distributed nanoparticles. A close-up view in Fig. 2(f) shows that there are two types of 

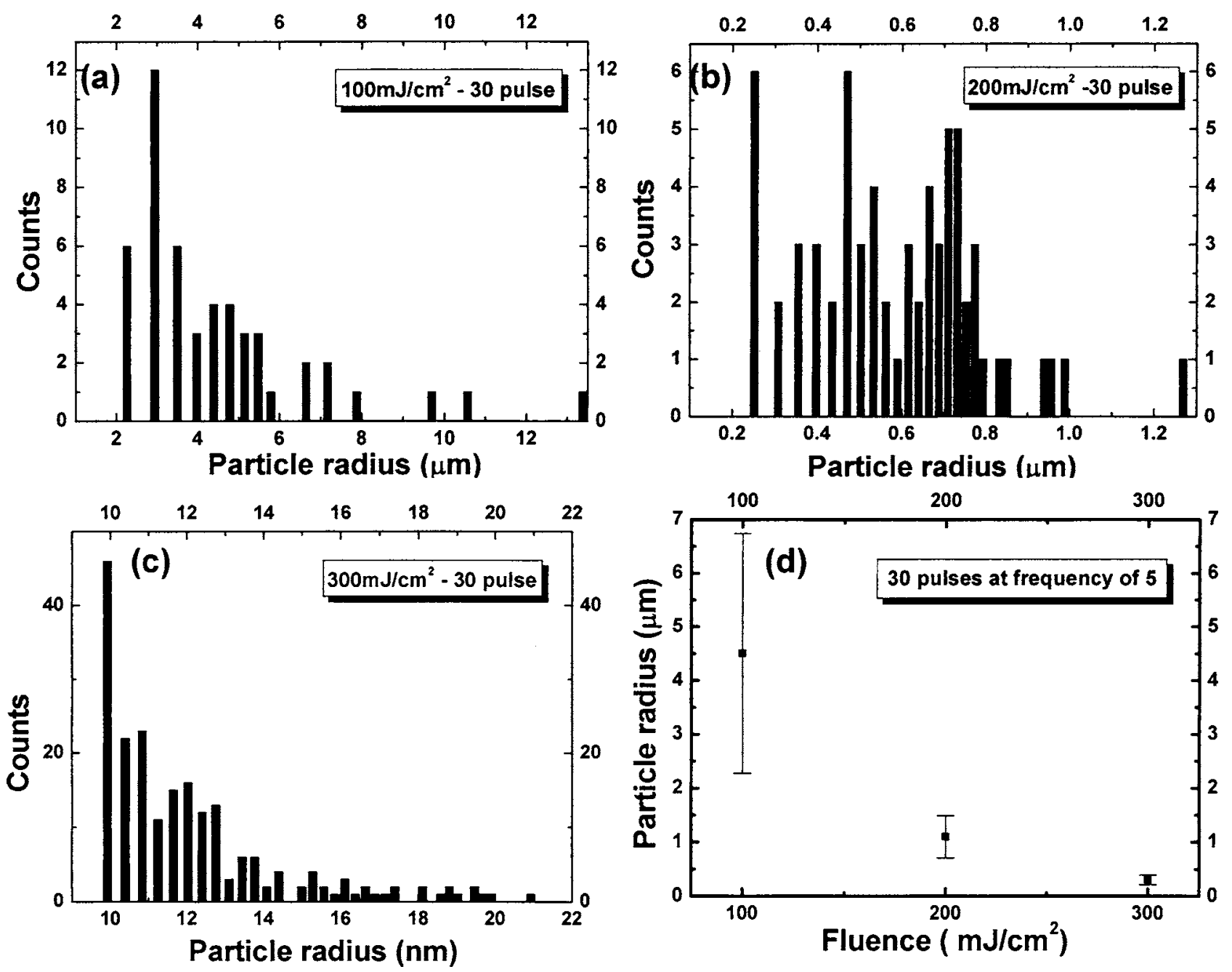

FIG. 3. Statistical analysis of particle size distribution as a function of laser fluence. Pulse number and pulse frequency were fixed at 30 and $5 \mathrm{~Hz}$ respectively. Histograms of size distributions of (a) $100 \mathrm{~mJ} / \mathrm{cm}^{2}$, (b) $200 \mathrm{~mJ} / \mathrm{cm}^{2}$, (c) $300 \mathrm{~mJ} / \mathrm{cm}^{2}$, and (d) average size of particles as a function of laser fluence.

particles: irregular-shaped submicrometer-sized clusters and nanoparticles with diameters approximately $10-20 \mathrm{~nm}$. From the AFM image [the inset of Fig. 2(f)], the irregular sub-100 nm clusters were actually composed of nanoparticles, with diameters approximately equal to or less than $20 \mathrm{~nm}$. It is suggested that at the initial several pulses, submicrometer-sized clusters were formed as the fragments of laser disintegrated microclusters. Nanoparticles could be generated from the subsequent bombardments of laser pulses.

Figures 3(a)-3(c) show the statistical size distribution of particles under laser irradiation at fluences of 100, 200, and $300 \mathrm{~mJ} / \mathrm{cm}^{2}$, respectively. Figure $3(\mathrm{~d})$ shows the average particle size as a function of laser fluence. At the fluences of 100,200 , and $300 \mathrm{~mJ} / \mathrm{cm}^{2}$, the average sizes of particles were $4.5,1.1$, and $0.015 \mu \mathrm{m}$, respectively. From the morphology changes in $\mathrm{NiSO}_{4}$ clusters and the statistical analysis, we found that increase in the laser fluences could effectively disintegrate large clusters into much smaller nanoparticles. Nanoparticles with a small size variation could be obtained.

Figure 4 shows SEM micrographs of $\mathrm{NiSO}_{4}$ clusters irradiated with different pulse numbers at a fluence of $300 \mathrm{~mJ} / \mathrm{cm}^{2}$. Figures 4(a) and 4(b) show the morphology of the sample irradiated for 5 pulses. $\mathrm{NiSO}_{4}$ clusters were partially disintegrated. A $3 \mu \mathrm{m} \mathrm{NiSO}$ cluster remained intact, whereas laser-induced pulverization did effectively break smaller clusters (up to $1-2 \mu \mathrm{m}$ ) into nanoparticles. When the pulse number was increased to 15 , large numbers of $\mathrm{NiSO}_{4}$ clusters were broken into pieces as shown in Fig. 4(c). Figure 4(d) shows the average size of the nanoparticles as a function of laser pulse number. The average sizes of the particles on the samples irradiated for 5, 15, and 30 pulses, were found to be 17,16 , and $11 \mathrm{~nm}$, respectively. This indicates that under repeated laser shot there was only a moderate decrease in the particle size. The ultimate size of the nanoparticles was directly dependent on the incident laser fluence. However, sufficient pulses are required to disintegrate $\mathrm{NiSO}_{4}$ microclusters into nanoparticles thoroughly when $\mathrm{NiSO}_{4}$ clusters are large.

\section{B. Mechanism of laser-induced pulverization of $\mathrm{NiSO}_{4}$}

The mechanisms of laser-material interaction depend on the laser wavelength, pulse duration and fluence. In a nanosecond pulsed-laser ablation regime (corresponding to a fluence from several to tens of joules per square centimeter), thermal, electronic, and hydrodynamic sputtering are major 

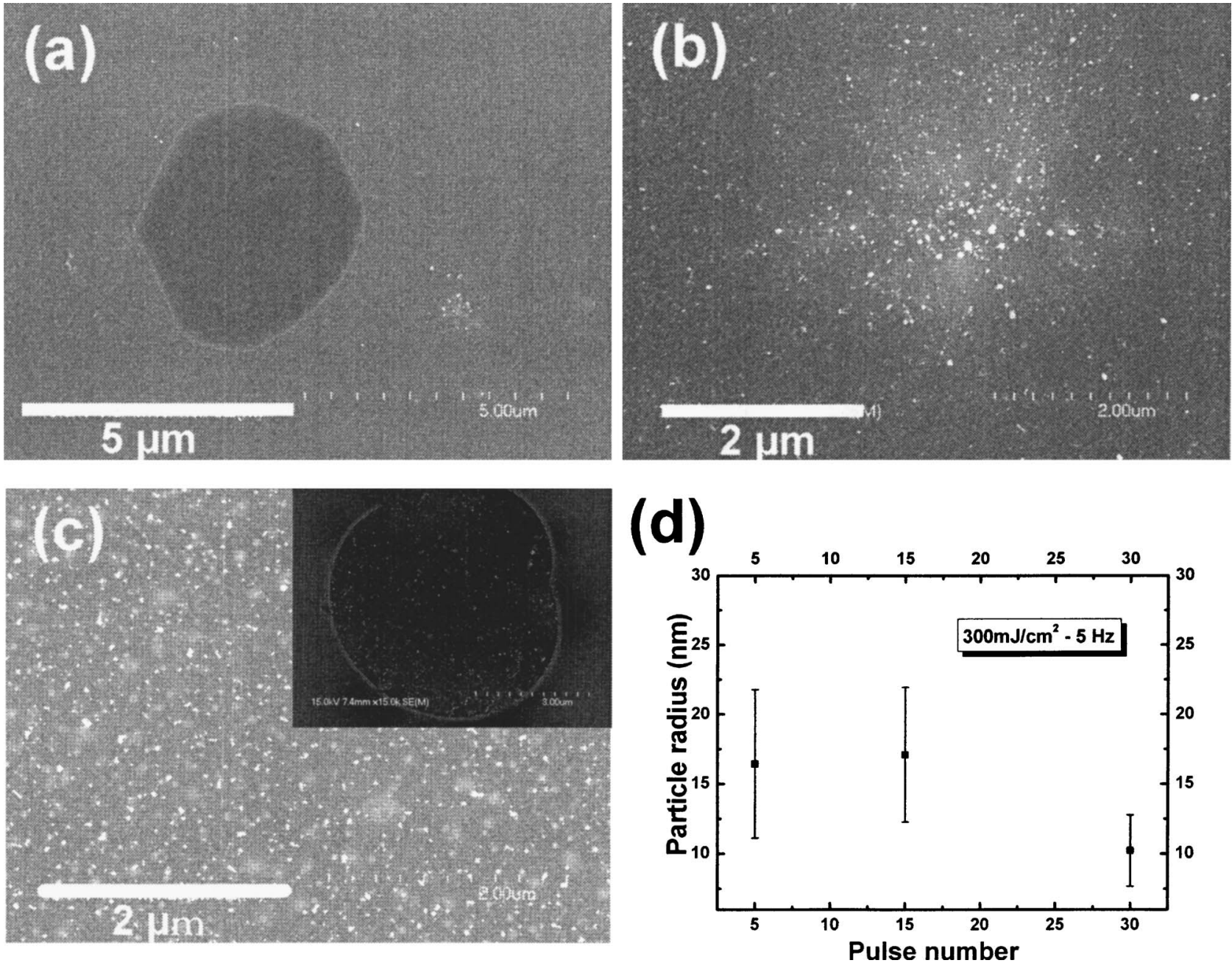

FIG. 4. SEM micrographs of a sample laser irradiated at $300 \mathrm{~mJ} / \mathrm{cm}^{2}$. (a) and (b) 5 pulses; (c) 15 pulses; the inset of (c) is a micrometer-sized particle under laser irradiation; and (d) average sizes of particles as a function of pulse number.

mechanisms responsible for substrate damages and material ejections. $^{26}$ In some cases, wide-band-gap materials such as LiF (Refs. 27 and 28) can be ablated both electronically and hydrodynamically ${ }^{27,28}$ although the photon energy is smaller than the band gap of the material (excimer laser at 248 and $193 \mathrm{~nm}$, corresponding to photon energy of 5 and $6.4 \mathrm{eV}$ respectively; $\mathrm{LiF}$ band gap: $13.6-14.5 \mathrm{eV})$. At a relatively lower laser fluence (in the order of $10-100 \mathrm{~mJ} / \mathrm{cm}^{2}$, below the ablation threshold), photothermal melting, photochemical decomposition, ${ }^{29}$ and transient thermal shock fragmentation $^{30}$ are among the main mechanisms.

In this study, EDX elemental analysis of $\mathrm{NiSO}_{4}$ clusters before and after laser irradiation was carried out to qualitatively examine the possible products under laser irradiation. Both nickel and sulfur were detected from samples irradiated at fluences from 100 to $300 \mathrm{~mJ} / \mathrm{cm}^{2}$. A coarse estimation of nickel and sulfur atomic ratio indicated that the amount of sulfur was quite similar as that of nickel on the sample surfaces irradiated with different fluences and pulses. Since thermal decomposition of $\mathrm{NiSO}_{4}$ would release $\mathrm{SO}_{2}$ and $\mathrm{O}_{2}$ gases and result in a much higher $\mathrm{Ni} / \mathrm{S}$ ratio, it is suggested that under the laser fluences used in the experiments, direct thermal decomposition and melting were not the main mechanisms for nanoparticles generation. Instead, physical pulverization played a main role in the generation a large portion of disintegrated subclusters and nanoparticles composed of nearly stoichiometric $\mathrm{NiSO}_{4}$.

To further investigate the fundamentals of this laser fragmentation process, one-dimensional heat transfer in laser irradiation on silicon was calculated using a computer program called "Simulation of Laser Interaction with Matter" (SLIM) developed by Singh et al. ${ }^{31}$ in which an implicit finite difference scheme is used to solve the heat flow equation. The validity of using this simplified model to estimate the surface temperature of the system was based on the fact that $\mathrm{SiO}_{2}$ and $\mathrm{NiSO}_{4}$ are highly transparent at $248 \mathrm{~nm} .{ }^{32}$ Considering the fact that sporadically distributed $\mathrm{NiSO}_{4}$ clusters (around $100 \mathrm{~nm}$ thick) have a relatively small surface coverage on the silicon substrate than the continuous film, we neglected the laser energy absorbed in $\mathrm{NiSO}_{4}$ as a coarse approximation. The temporal profile of the incident laser was modeled to be a Gaussian function with a pulse width of 23 ns. In Fig. 5, peak temperatures for single pulse irradiation at fluences of 100,200 , and $300 \mathrm{~mJ} / \mathrm{cm}^{2}$ are calculated to be 150,260 , and $395^{\circ} \mathrm{C}$, respectively, which are much lower than the thermal decomposition temperature of $\mathrm{NiSO}_{4}$ around $849{ }^{\circ} \mathrm{C} .{ }^{33}$ As indicated previously, $\mathrm{NiSO}_{4}$ disintegration in this study could be due to the transient thermal ex- 


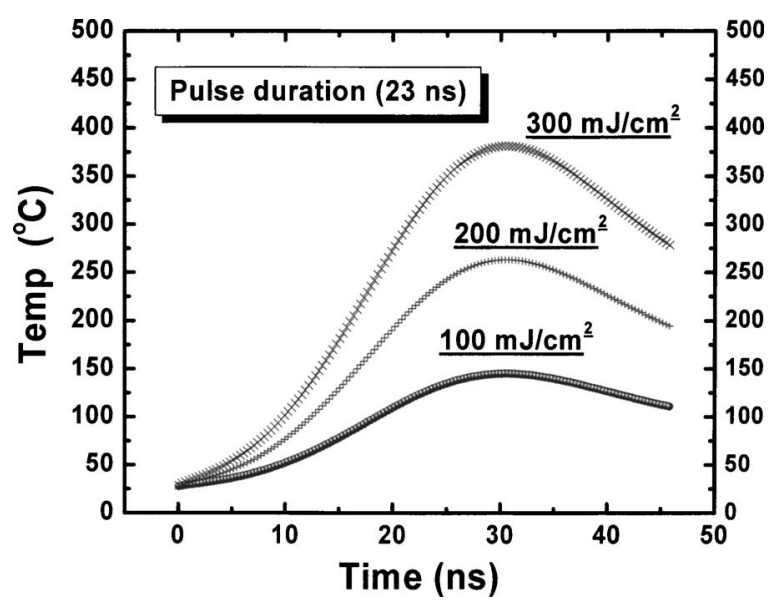

FIG. 5. Simulated temperature rise on silicon surface as a function of time under excimer laser irradiation.

pansion of the Si substrates, which was similar to the mechanism of dry laser cleaning. ${ }^{34}$ At the interface of $\mathrm{NiSO}_{4}$ clusters and $\mathrm{Si}$ surfaces, the adhesion force was mainly van der Waals force. Fast thermal expansion of the silicon substrates after laser irradiation could induce deformations in the normal direction. Zhen et al. calculated the surface deformation, velocity and acceleration of silica particles on $\mathrm{Si}$ substrates when the $\mathrm{SiO}_{2}$ spheres/Si system was under excimer laser irradiation. ${ }^{34}$ It was found that the surface deformation, velocity and acceleration increased with the transient temperature increase. At a transient maximum temperature around $400{ }^{\circ} \mathrm{C}$ (approximately the same as the temperature at $300 \mathrm{~mJ} / \mathrm{cm}^{2}$ in this study), a maximum surface deformation, velocity and acceleration were found to be $1 \mathrm{~nm}$, $12 \mathrm{~cm} / \mathrm{s}$, and $4 \times 10^{9} \mathrm{~cm} / \mathrm{s}^{2}$, respectively. Silica particles with diameters from 1 to $5 \mu \mathrm{m}$ can jump around several millimeters above the substrate surface during laser cleaning. ${ }^{34}$ In this study, $\mathrm{NiSO}_{4}$ clusters may crack and break into irregular shaped subclusters due to the fast thermal expansion of the substrates under excimer laser irradiation. Although the physical thermal transient expansion was suggested to be the main mechanism responsible for $\mathrm{NiSO}_{4}$ pulverization, we cannot exclude the possibility of melting of $\mathrm{NiSO}_{4}$ nanoparticles under irradiation of multiple pulses. The melting point of nano-clusters might be much lower than the bulk material. With multipulse irradiation, local decomposition at defects would result in Ni rich areas, which might initiate enhanced absorption of laser energy and induce melting. Further characterizations of the products under such multipulse irradiation will be carried out to discover and differentiate the underlying entangling mechanisms.

\section{Catalytic growth of CNTs/CNFs}

Figure 6 shows the SEM micrographs of CNTs/CNFs grown from the catalysts prepared with different laser fluences. Figures 6(a) and 6(b), corresponding to laser irradiation for 30 pulses at $100 \mathrm{~mJ} / \mathrm{cm}^{2}$, show that large amount of CNTs/CNFs grew out of $\mathrm{NiSO}_{4}$ microclusters and bundled into cauliflower-like CNT/CNF islands. Figures 6(c) and 6(d) show the SEM micrographs of CNTs/CNFs grown from the catalysts prepared at $200 \mathrm{~mJ} / \mathrm{cm}^{2}$ for 30 pulses. Smaller
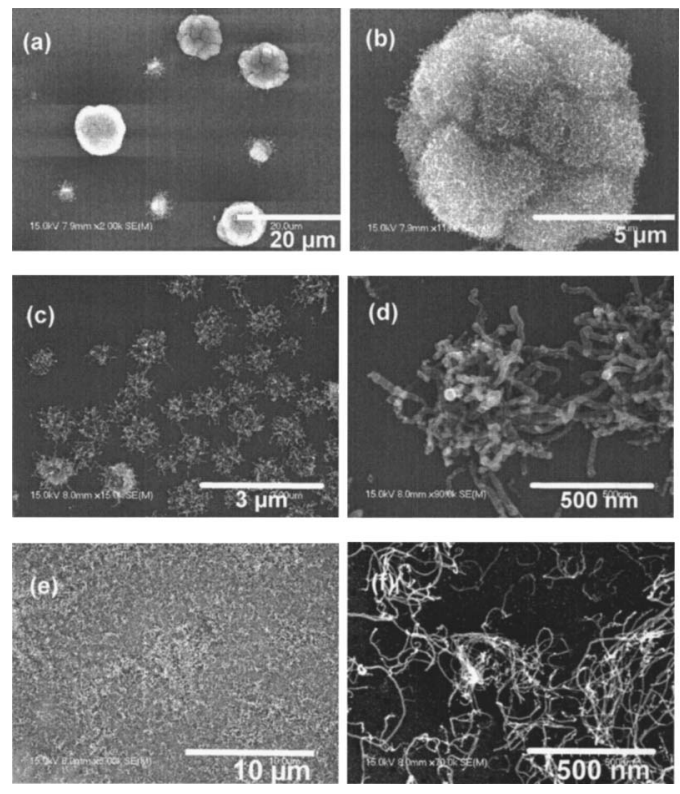

FIG. 6. SEM micrographs of carbon nanotubes/nanofibers grown from catalysts prepared at different laser fluences. (a) and (b) $100 \mathrm{~mJ} / \mathrm{cm}^{2}$; (c) and (d) $200 \mathrm{~mJ} / \mathrm{cm}^{2}$; and (e) and (f) $300 \mathrm{~mJ} / \mathrm{cm}^{2}$. Pulse numbers were fixed at 30 pulses.

bunches of dendritic CNTs/CNFs were found on the silicon substrate sporadically, with average diameters of individual fibers ranging from 50 to $100 \mathrm{~nm}$. A similarity among CNTs/ CNFs shown in Figs. 6(a)-6(d) is that they grew almost radically outward, with their base rooted at the original $\mathrm{NiSO}_{4}$ microclusters. Figures 6(e) and 6(f) show CNTs/CNFs grown from the catalysts prepared at $300 \mathrm{~mJ} / \mathrm{cm}^{2}$ for 30 pulses. $\mathrm{CNT} / \mathrm{CNF}$ islands and bunches were not observed. Instead, a large area of substrate was densely covered by CNTs/CNFs with diameters ranging from $10-20 \mathrm{~nm}$. In order to investigate the structures of the CNTs/CNFs, HRTEM was used for morphology characterization and electron diffraction. As shown in Figs. 7(a) and 7(b), carbon fibers with solid interior structures were identified for samples irradiated at $200 \mathrm{~mJ} / \mathrm{cm}^{2}$ for 30 pulses. Ni particles (dark particles) were embedded in the tips of CNFs, with the size similar to the diameter of CNFs. Both herringbone (or fishbone) type and bamboo type (indicated by the arrows) were identified. The corresponding selected-area electron diffraction pattern showed (0002) and (1 $1 \overline{100)}$ graphene planes (corresponding to stacked graphitic layers in CNFs) and (200) nickel plane respectively. Figures $7(\mathrm{c})$ and $7(\mathrm{~d})$ show the TEM micrograph and convergent beam electron diffraction pattern of CNTs grown from the sample irradiated at $300 \mathrm{~mJ} / \mathrm{cm}^{2}$ for 30 pulses. External diameters of CNTs with hollow cylinders were in a range of 10-20 nm. As shown in Fig. 7(d), an electron beam with diameter of $8 \mathrm{~nm}$ was focused on a single tube. Graphite (0002) and $(000 \overline{2})$ were identified, indicating vertical planes of aligned CNTs. (1500) graphite plane was also identified in Fig. 7(d).

CNTs and CNFs are similar two-dimensional stacking graphene structures, with different angles between fiber axis and graphene sheet stacking direction. ${ }^{35}$ The former refers to graphene sheets forming cylinders, whereas the latter refers 


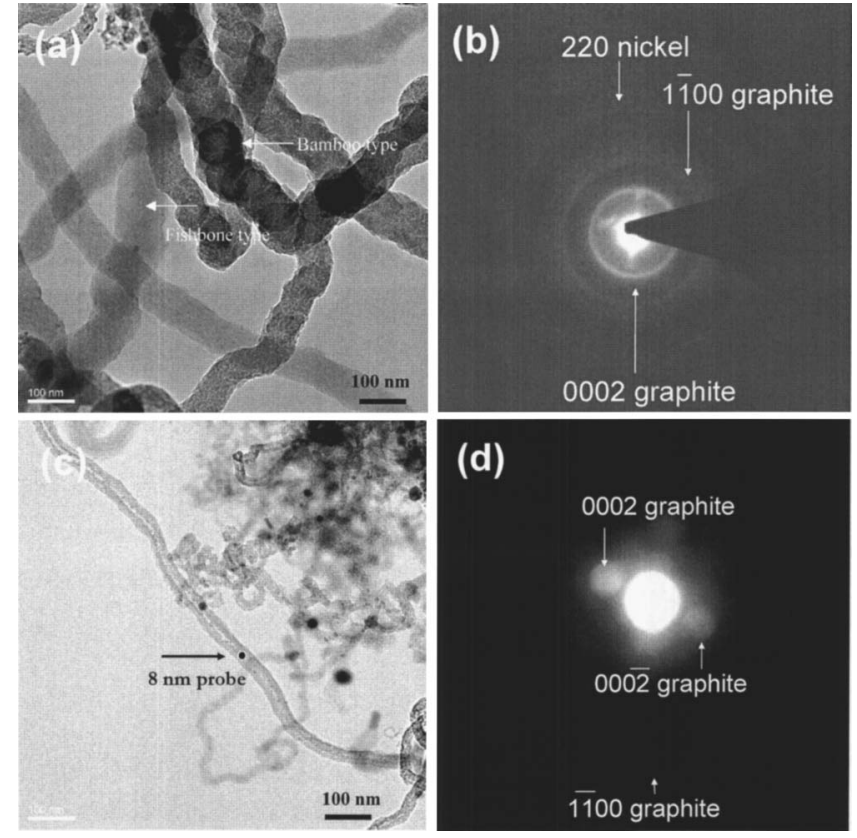

FIG. 7. (a) TEM micrograph of carbon nanofibers grown on samples irradiated at $200 \mathrm{~mJ} / \mathrm{cm}^{2}, 30$ pulses; (b) the selected area electron diffraction pattern obtained in (a); (c) TEM micrograph of carbon nanotubes irradiated at $300 \mathrm{~mJ} / \mathrm{cm}^{2}, 30$ pulses; and (d) the converged beam electron diffraction pattern of the area pointed in (c), with a probe size of $8 \mathrm{~nm}$.

to cone- and cup-structured graphene stacking. CNFs are found to have similar electronic and mechanical properties as multiwalled carbon nanotubes (MWCNT). ${ }^{1,35}$ Today, diffusion model is widely accepted for catalytic growth of both CNFs and CNTs, ${ }^{36,37}$ which originated from the vapor-liquidsolid mechanism for growth of whiskers (currently know as fibers) back to the $1960 \mathrm{~s} .{ }^{38}$ As described in diffusion model, CNF/CNT deposition process usually consists of three steps: First, reactant carbon feedstock molecules (hydrocarbon or carbon containing compounds) adsorb and decompose on the surface of a catalyst; second, carbon species dissolve or diffuse into catalyst particles (usually in a liquid state); finally, carbon precipitates on opposite surface of the catalyst forming nanofiber/nanotube structures. ${ }^{35}$ The growth modes for CNTs and CNFs include both tip-type and base-type. However, difference in the growth behavior between CNFs and CNTs is still not fully understood. Nevertheless, Ni particles as catalysts have been widely studied for catalytic growth for both CNFs and MWCNT. ${ }^{10,39}$ It is found that the contact angle of the catalyst with the supporting surface greatly affects the growth behavior. ${ }^{15}$ When the catalyst has multifaceted shape (such as cone-like structures) with flat surfaces facing substrates, graphene layers tend to bend parallel to the flat surface of the catalysts. In this manner, fishbone-type CNFs will be formed by graphene layer precipitation directly under these surfaces, which lifted the Ni particles from the surface. ${ }^{35}$

From SEM and TEM micrographs, we found that the initial size of $\mathrm{NiSO}_{4}$ clusters/nanoparticles determined diameters of $\mathrm{CNTs} / \mathrm{CNFs}$. For $\mathrm{NiSO}_{4}$ micro- or submicrometerclusters, corresponding to samples irradiated at 100 and $200 \mathrm{~mJ} / \mathrm{cm}^{2}$, thermal decomposition of $\mathrm{NiSO}_{4}$ took place during the CNT/CNF growth in the HFCVD chamber. In the

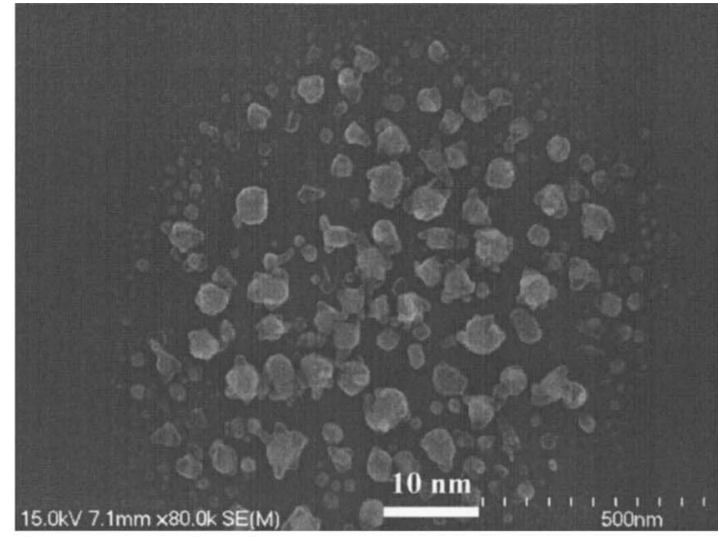

(a)

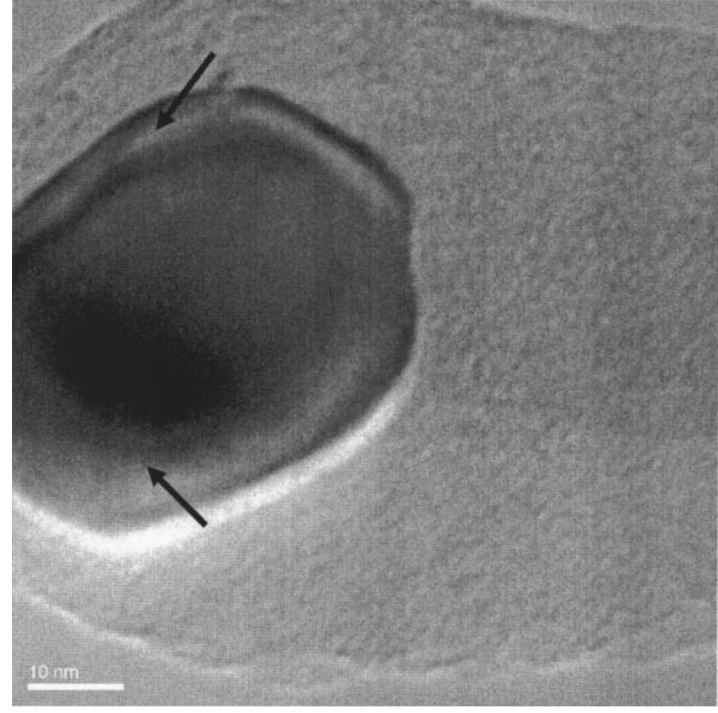

(b)

FIG. 8. (a) SEM micrograph of thermally annealed $\mathrm{NiSO}_{4}$ on $\mathrm{Si}$ substrates in vacuum at $900{ }^{\circ} \mathrm{C}$ for $10 \mathrm{~min}$; and (b) TEM micrograph of a CNF with a $\mathrm{Ni}$ nanoparticle in the tip.

process of thermal decomposition of $\mathrm{NiSO}_{4}$, there might be aggregation of $\mathrm{Ni}$ atoms, accompanied by adsorption of carbon species onto the surface simultaneously. We suggest that localized $\mathrm{SO}_{2} / \mathrm{O}_{2}$ gases be released from $\mathrm{NiSO}_{4}$ molecules (surrounding $\mathrm{Ni}$ atoms), which might segregate or dilute the carbon species, keeping them from dissolving into Ni catalysts to initiate CNT growth. From the SEM and TEM micrographs, we can deduce that the CNF started to form after Ni aggregating into 40-50 nm sized, multifaceted nanoparticles. As a comparison, a SEM micrograph of Ni nanoparticles from direct pyrolysis of as-deposited $\mathrm{NiSO}_{4}\left(900{ }^{\circ} \mathrm{C}\right.$ for $15 \mathrm{~min}$ in vacuum) is shown in Fig. 8(a). The sizes of these Ni nanoparticles were in the 50-100 $\mathrm{nm}$ range. The shapes were irregularly multifaceted. As shown in Fig. 8(b), an irregularly shaped Ni catalyst particle with two downward faces (indicated by the arrows) was embedded in the tip of a CNF. Such downward faces would cause graphene layers to bend, to favor fishbone-type CNF growth. For samples under laser irradiation at $300 \mathrm{~mJ} / \mathrm{cm}^{2}$, fine $(10-20 \mathrm{~nm})$ and nearly spherical $\mathrm{NiSO}_{4}$ nanoparticles were obtained [Fig. 2(f)]. During the thermal decomposition of $\mathrm{NiSO}_{4}$, the carbon species can penetrate and dissolve into Ni particles at an earlier 
stage to initiate small-diameter CNT growth. As a result, MWCNTs with smaller diameters were preferentially synthesized.

\section{CONCLUSION}

We have demonstrated a method to produce $\mathrm{Ni}$ nanocatalysts by irradiating dispersed $\mathrm{NiSO}_{4}$ microclusters on silicon substrates using a $\mathrm{KrF}$ excimer laser. The size distributions of clusters/nanoparticles were found to be determined by both laser fluence and pulse number. By increasing laser fluence from 100 to $300 \mathrm{~mJ} / \mathrm{cm}^{2}$, the average size of disintegrated particles was drastically decreased, from several micrometers to several nanometers. It was suggested that laser-induced disintegration be mainly due to the physical fragmentation by transient thermal expansion/contraction of substrates under pulsed-laser irradiation. The possibility of nanoparticle thermal melting under multipulse irradiation was also suggested. Hot-filament chemical vapor deposition was used for growth of CNTs from pulsed-laser prepared catalysts. For samples irradiated at 100 and $200 \mathrm{~mJ} / \mathrm{cm}^{2}$, CNFs were dominant products. These CNFs grew radially out of large $\mathrm{NiSO}_{4}$ clusters, forming dendritic CNF bunches. For catalysts prepared at $300 \mathrm{~mJ} / \mathrm{cm}^{2}$, multiwalled CNTs with uniform diameters were obtained. We suggest that $\mathrm{Ni}$ atoms aggregate through thermal decomposition of $\mathrm{NiSO}_{4}$ clusters/nanoparticles during HFCVD. The size and the shape of the Ni aggregation, which were determined by the initial size of $\mathrm{NiSO}_{4}$ clusters/nanoparticles, might affect the preference in the synthesis of CNT or CNFs.

\section{ACKNOWLEDGMENT}

The authors would like to thank Dr. Kit Lee from the Department of Biology at the University of NebraskaLincoln for the SEM and EDX measurements. The authors also want to thank Dr. Stuart McKernan at the University of Minnesota for HRTEM measurements. This work was financially supported by Nebraska Research Initiative, National Science Foundation, and Research Foundation for OptoScience and Technology (Japan).

${ }^{1}$ M. S. Dresselhaus, G. Dresselhaus, and P. Avouris, Carbon Nanotubes: Synthesis, Structure, Properties and Applications (Springer, Berlin, 2001). ${ }^{2}$ W. A. de Heer, A. Châtelain, and D. Ugarte, Science 270, 1179 (1995).

${ }^{3}$ Q. H. Wang, T. D. Corrigan, J. Y. Dai, R. P. H. Chang, and A. R. Krauss, Appl. Phys. Lett. 70, 3308 (1997).

${ }^{4}$ Y. Zhou, A. Gaur, S.-H. Hur, C. Kocabas, M. A. Meitl, M. Shim, and J. A. Rogers, Nano Lett. 4, 2031 (2004).

${ }^{5}$ R. Seidel, A. P. Graham, E. Unger, G. S. Duesberg, M. Liebau, W. Steinhoegl, F. Kreupl, and W. Hoenlein, Nano Lett. 4, 831 (2004).
${ }^{6}$ S. Chopra, A. Pham, J. Gaillard, A. Parker, and A. M. Rao, Appl. Phys. Lett. 80, 4632 (2002).

${ }^{7}$ A. Thess et al. Science 273, 5274 (1996).

${ }^{8}$ T. W. Ebbesen and P. M. Ajaya, Nature (London) 358, 220 (1992).

${ }^{9}$ J. Kong, A. M. Cassell, and H. Dai, Chem. Phys. Lett. 292, 567 (1998).

${ }^{10}$ Z. F. Ren, Z. P. Huang, J. W. Xu, J. H. Wang, P. Bush, P. Siegal, and P. N. Provencio, Science 282, 1105 (1998)

${ }^{11}$ Y. Tzeng, C. Liu, and Z. Chen, Mater. Res. Soc. Symp. Proc. 621, R751 (2000).

${ }^{12}$ F. Rohmund, R.-E. Morjan, G. Ledoux, F. Huisken, and R. Alexandrescu, J. Vac. Sci. Technol. B 20, 802 (2002).

${ }^{13}$ J. I. Sohn, C. J. Choi, S. Lee, and T. Y. Seong, Appl. Phys. Lett. 78, 3130 (2001).

${ }^{14}$ G. S. Choi, Y. S. Cho, S. Y. Hong, J. B. Park, K. H. Son, and D. J. Kim, J. Appl. Phys. 91, 3847 (2002).

${ }^{15}$ M. Chhowalla, K. B. K. Teo, C. Ducati, N. L. Rupesinghe, G. A. J. Amaratunga, A. C. Ferrari, D. Roy, J. Robertson, and W. I. M. Milne, J. Appl. Phys. 90, 5308 (2001).

${ }^{16}$ J. D. Carey, L. L. Ong, and S. R. P. Silva, Nanotechnology 14, 1223 (2003).

${ }^{17}$ M. Cassell, S. Verma, L. Delzeit, M. Meyyappan, and J. Han, Langmuir 17, 260 (2001).

${ }^{18}$ J. S. Gao, K. Umeda, K. Uchino, H. Nakashima, and K. Muraoka, Mater. Sci. Eng., B 107, 113 (2004).

${ }^{19}$ N. Grobert et al., Appl. Phys. A: Mater. Sci. Process. 70, 175 (1997).

${ }^{20}$ S. J. Henley, C. H. P. Poa, A. A. D. T. Adikaari, C. E. Giusca, J. D. Carey, and S. R. P. Silva, Appl. Phys. Lett. 84, 4035 (2004).

${ }^{21}$ J. Bosbach, D. Martin, F. Stietz, T. Wenzel, and F. Traeger, Appl. Phys. Lett. 74, 2605 (1999)

${ }^{22}$ D. Q. Yang, M. Meunier, and E. Sacher, J. Appl. Phys. 95, 5023 (2004).

${ }^{23}$ M. Kawasaki and M. Hori, J. Phys. Chem. 107, 6760 (2003).

${ }^{24}$ K. B. Lee and L. W. Lin, Sens. Actuators, A 111, 44 (2004).

${ }^{25} \mathrm{~W}$. Rasband, "Image J1.33u," http://rsb.info.nih.gov/ij.

${ }^{26} \mathrm{R}$. Kelly and A. Miotello, "Mechanisms of Pulsed Laser Sputtering" in Pulsed Laser Deposition of Thin Films, edited by D. B. Chrisey and G. K. Hubler, Wiley, New York, 1994.

${ }^{27}$ A. Perea, J. Gonzalo, C. N. Afonso, S. Martelli, and R. M. Montereali, Appl. Surf. Sci. 138, 533 (1999).

${ }^{28}$ S. J. Henley, M. N. R. Ashfold, and S. R. J. Pearce, Astron. Soc. Pac. 217, 68 (2003).

${ }^{29}$ K. Hatanaka, M. Kawao, Y. Tsuboi, H. Fukumura, and H. Masuhara, J. Appl. Phys. 82, 5799 (1997).

${ }^{30}$ T. Masubuchi, T. Tada, E. Nomura, K. Hatanaka, H. Fukumura, and H. Masuhara, J. Phys. Chem. B 106, 2180 (2002).

${ }^{31}$ Rajiv K. Singh and J. Viatella, SLIM is a copyrighted program developed at the Materials Science and Engineering Department at the University of Florida, Gainesville, FL 32611-6550.

${ }^{32}$ X. X. Zhuang, G. B. Su, G. F. Wang, G. H. Li, and Z. X. Huang, Cryst. Res. Technol. 39, 754 (2004)

${ }^{33}$ R. F. Karlicek, V. M. Donnelly, and G. J. Collins, J. Appl. Phys. 53, 1084 (1982).

${ }^{34}$ Y. W. Zheng, Ph.D. dissertation, National University of Singapore, Singapore (2002).

${ }^{35}$ V. Melechko, V. I. Merkulov, T. E. Mcknight, M. A. Guillorn, K. L. Klein, D. H. Lowndes, and M. L. Simpson, J. Appl. Phys. 97, 041301 (2005).

${ }^{36}$ H. Kanzow and A. Ding, Phys. Rev. B 60, 11180 (1999).

${ }^{37}$ N. M. Rodriguez, J. Mater. Res. 8, 3233 (1993).

${ }^{38}$ R. Bacon, J. Appl. Phys. 31, 283 (1960).

${ }^{39}$ S. Helveg, C. Lopez-Cartes, J. Sehested, P. L. Hansen, B. S. Clausen, J. R. Rostrup-Nielsen, F. Abild-Pedersen, and J. K. Norskov, Nature (London) 427, 426 (2004) 